\title{
Past and Present: A Review of Antenatal Corticosteroids and Recommendations for Late Preterm Birth Steroids
}

\author{
C. Luke Dixon, MD ${ }^{1}$ Gloria Too, MD ${ }^{2}$ George R. Saade, MD ${ }^{1}$ Cynthia Gyamfi-Bannerman, MD ${ }^{3}$
}

${ }^{1}$ Department of Obstetrics and Gynecology, The University of Texas Medical Branch at Galveston, Galveston, Texas

2 Department of Obstetrics and Gynecology, Eastern Virginia Medical School, Norfolk, Virginia

${ }^{3}$ Department of Obstetrics and Gynecology, Columbia University, New York, New York

Am J Perinatol 2018;35:1241-1250.

\author{
Address for correspondence C. Luke Dixon, MD, Department of \\ Obstetrics and Gynecology, The University of Texas Medical Branch at \\ Galveston, 301 University Boulevard, Galveston, TX 77555-0587 \\ (e-mail: cldixon@utmb.edu).
}

\author{
Abstract \\ Keywords \\ - antenatal \\ corticosteroids \\ - betamethasone \\ - dexamethasone \\ - fetal \\ - maturity \\ - late preterm steroids
}

Since 1972, the beneficial neonatal effects of antenatal corticosteroids (ACSs) have been repeatedly demonstrated in pregnancies at risk of preterm birth before 34 weeks' gestation. While ACS utilization before 34 weeks has been high since the 1990s, knowledge gaps regarding the risks and benefits of ACS continue to exist. Recent evidence has been published regarding the benefit of ACS in the late preterm period. This review addresses the evidence and knowledge gaps for ACS use before and after 34 weeks' gestation. We also provide recommendations for ACS use in the late preterm period.

\section{Review of Steroids before 34 Weeks}

Forty-five years ago, Liggins and Howie demonstrated that antenatal corticosteroid (ACS) use could significantly decrease respiratory distress syndrome (RDS) in live born infants less than 32 weeks' gestation. ${ }^{1}$ Follow-up studies confirmed the beneficial effect of ACS on RDS $^{2-4}$ and subsequently, several articles were published detailing the additional beneficial effects of ACS on other neonatal outcomes. In 1990, Crowley et al performed a systematic review and meta-analysis of 12 trials demonstrating a significant decrease in RDS, intraventricular hemorrhage (IVH), necrotizing enterocolitis (NEC), and neonatal death in neonates exposed to corticosteroids. ${ }^{5}$ In 1994 , based on these and other results, a National Institutes of Health (NIH) consensus development panel published recommendations for treatment of all fetuses between 24 and 34 weeks' gestation at risk of preterm delivery. ${ }^{3}$

received

December 22, 2017

accepted after revision

April 8, 2018

published online

May 23, 2018
Knowledge gaps at the time that needed to be addressed in future research included repeat ACS and long-term cognitive, behavioral, psychological, and physical development outcomes. ${ }^{3}$ These recommendations were reaffirmed by the $\mathrm{NIH}$ and received support from the American College of Obstetricians and Gynecologists (ACOG) Committee on Obstetric Practice in May, 2002. ${ }^{6}$ At that time, the evidence regarding the use of ACS after 34 weeks' gestation was considered inadequate to recommend for or against its use; it was only to be used if there was evidence of fetal pulmonary immaturity. For many years now, a single course of ACS for fetuses between 24 and 34 weeks' gestation at risk of preterm birth has been a mainstay in obstetrical practice. The most recent Cochrane review and meta-analysis of 30 studies (7,774 women and 8,158 infants) found a reduction in perinatal death, neonatal death, RDS, IVH, NEC, need for mechanical ventilation, and systemic infections in those treated with ACS. ${ }^{7}$

Copyright $\odot 2018$ by Thieme Medical Publishers, Inc., 333 Seventh Avenue, New York, NY 10001, USA. Tel: +1(212) 584-4662.
DOI https://doi.org/ 10.1055/s-0038-1653944. ISSN 0735-1631. 


\section{Remaining Knowledge Gaps for Steroids before 34 Weeks}

\section{Periviable Birth}

While the use of ACS between 24 and 34 weeks' gestation has been steadfast, there has been some controversy surrounding other aspects of ACS administration. Periviable birth has recently been defined as delivery occurring from $20^{0 / 7}$ to $25^{6 / 7}$ weeks' gestation. ${ }^{8}$ While long-term morbidity of surviving periviable infants is very high, the survival rates vary based on institutional practices regarding initiation of resuscitation. Survival is as high as $27 \%$ for births at 23 weeks and $59 \%$ for births at 24 weeks. ${ }^{8,9}$ Recently, a study compared survival and neurodevelopmental outcomes of 4,274 infants born at 22 to 24 weeks' gestation, across three consecutive birth-year epochs (2000-2003, 2004-2007, and 2008-2011). They determined that the rate of survival with neurodevelopmental impairment compared with death (adjusted relative risk [aRR]: $1.27,95 \%$ confidence interval [CI]: 1.01-1.59) and the rate of survival without neurodevelopmental impairment compared with death (aRR: 1.59, 95\% CI: 1.28-1.99), increased over time. In this study, the rate of ACS use increased with time, however, this variable was left out of the analysis, so the temporal effect would not be obscured. When analysis was restricted to infants who received active treatment, the study outcomes were unchanged, making it unlikely that the increased rate of survival was due to the increase in ACS use. ${ }^{10}$ In a 2011 cohort study, ACS was found to reduce death, $\mathrm{IVH}$, periventricular leukomalacia, NEC, and neurodevelopmental impairment at 18 to 22 months for those exposed to ACS at 23 to 25 weeks' gestation. ${ }^{11}$ These associations have been confirmed in additional studies. ${ }^{12-15}$ None of these studies, however, were randomized trials. Due to the relatively low volume and complexity of periviable deliveries, randomized trials are highly unlikely. In 2014, a joint workshop among Society for Maternal-Fetal Medicine (SMFM), ACOG, National Institute of Child Health and Human Development (NICHD), and American Academy of Pediatrics (AAP) provided recommendations for periviable birth. For threatened or imminent periviable birth, they recommended to consider ACS for women at risk of delivery between $22^{0 / 7}$ and $22^{6 / 7}$ weeks' gestation, and recommended the use of corticosteroids for all women at risk of preterm birth $\geq 23$ weeks' gestation. ${ }^{16}$ This recommendation has since been amended by ACOG and SMFM to consider ACS at $23^{0 / 7}$ to $23^{6 / 7}$ weeks, and recommend its use for all births $\geq 24$ weeks' gestation. ${ }^{8}$ To assist in the counseling of patients regarding possible outcomes of periviable birth, the NICHD provides an online calculator that estimates survival, survival without neurodevelopmental impairment, and death. ${ }^{17}$

\section{Fetal Growth Restriction}

Concerns regarding the effect of ACS on growth-restricted fetuses arose when Liggins and Howie found an increase in fetal death in a subgroup of women with severe hypertension, proteinuria, fetal growth restriction and low urinary estrogen. ${ }^{1}$ Since, studies evaluating the outcomes of growthrestricted fetuses treated with ACS versus no intervention yielded conflicting results. A recent study found no difference in RDS, IVH, NEC, and neonatal mortality. ${ }^{18}$ Another found a decreased neonatal mortality and overall neonatal morbidity. ${ }^{19}$ In a 2009 review of the literature, Torrance et al concluded that the effect of ACS on neonatal outcomes of intrauterine growth restricted (IUGR) fetuses remains inconclusive, and IUGR fetuses with abnormal umbilical artery Doppler studies treated with ACS did not have a significant alteration in the incidence of RDS, IVH, NEC, or neonatal mortality. ${ }^{20}$ In IUGR fetuses with abnormal umbilical artery Doppler blood flow, some studies have demonstrated a transient improvement in the umbilical artery Doppler blood flow, ${ }^{21-24}$ while others have not. ${ }^{25,26}$ This divergence in effect has caused some to hypothesize that IUGR fetuses without a transient improvement in umbilical artery Doppler flow may be at a higher risk for perinatal complications and hemodynamic decompensation after ACS administration. ${ }^{23,24}$ IUGR fetuses are exposed to more endogenous steroids due to a reduced expression of $11 \beta$-hydroxysteroid dehydrogenase type-2, which prevents maternal steroids from crossing the placenta. This physiologic change may reduce the effect of exogenous steroids on an IUGR fetus. ${ }^{20}$ With a lack of randomized controlled trials (RCTs) addressing this population, others have expressed desire to conduct a definitive trial. ${ }^{27}$ The current recommendations for ACS use do not differentiate between IUGR and non-IUGR fetuses.

\section{Multifetal Gestations}

Similarly, the effect of ACS in multifetal gestations remains understudied. While multiple gestations were included in the ACS trials, there is no trial that definitively addresses this group of patients. A subgroup analysis in the 2006 Cochrane review on ACS revealed no differences in RDS, cerebroventricular hemorrhage, and neonatal death in multifetal gestations treated with ACS compared with those untreated. ${ }^{28}$ of note, the direction and magnitude of the relative risks for these outcomes in multifetal gestation were similar to the analysis in the overall groups; however, the number of patients with multifetal gestation was small and mostly from two studies. ${ }^{28}$ A subsequent Cochrane review confirmed these findings and also found no evidence that ACS work differently in singleton versus multifetal gestation. ${ }^{7}$ A pharmacokinetic study suggests the half-life of betamethasone is significantly shorter in twin pregnancies and the volume of distribution is unchanged when comparing twin and singleton gestations; however, clinical outcomes were not assessed. ${ }^{29}$ Maternal and umbilical cord blood concentrations of betamethasone were similar in singleton and twin pregnancies. ${ }^{30}$ Studies on the effect of corticosteroids on multifetal gestations would need to be adequately powered to demonstrate a difference. Although lacking evidence, expert opinion recommends ACS for multiple gestations at risk of preterm birth between 24 and 34 weeks' gestation. ${ }^{31}$

\section{Maternal Obesity}

Pre-pregnancy obesity continues to rise in the United States, increasing from $18 \%$ in 2003 to $26 \%$ in $2014 .^{32,33}$ In obese patients, there is a theoretical concern that intramuscular 
medications are less effective because of altered body weight distribution, decreased lean muscle mass, alterations of pharmacokinetics, and the inadequate length of standard needles to reach the intramuscular space. ${ }^{34,35}$ Studies that have addressed betamethasone efficacy in this population have reported no difference in rates of RDS or umbilical cord blood concentrations of betamethasone in these patients. ${ }^{30,36}$ These studies were secondary analyses of existing data and were limited by the number of patients enrolled in the parent trials and further studies are needed to validate these findings.

\section{Preterm Premature Rupture of Membranes}

ACS has not been adequately or specifically evaluated in the setting of preterm premature rupture of membranes (PPROM). However, systematic reviews have demonstrated a reduction in fetal and neonatal death, RDS, IVH, and NEC in this subgroup. ${ }^{7,28}$ Initially, there was concern for the risk of maternal and neonatal infection in those treated with ACS, a concern which was not confirmed in the systematic reviews. ${ }^{7,28} \mathrm{~A}$ recent study found that even a second ACS is not associated with higher rates of neonatal sepsis. ${ }^{37}$ As further evidence of safety, in the setting of histologic chorioamnionitis, treatment with ACS decreases the incidence of RDS, IVH, neonatal mortality, and adverse neurologic outcomes without increasing neonatal sepsis. ${ }^{38,39}$ Overall consensus opinion is to administer corticosteroids for threatened delivery in the setting of PPROM before 34 weeks' gestation. ${ }^{40}$

\section{Type of Corticosteroid}

The ideal choice of ACS continues to be debated. Betamethasone and dexamethasone are both fluorinated steroids with nearly identical structures. ${ }^{41}$ The recommended regimens of two doses of $12 \mathrm{mg}$ of betamethasone intramuscularly every 24 hours or four doses of $6 \mathrm{mg}$ of dexamethasone every 12 hours has not changed since the original recommendations by the NIH consensus development panel. ${ }^{3}$ While both regimens provide demonstrable benefits, there are studies reflecting differences between the two types. Lee et al and Feldman et al found betamethasone to be associated with a reduced risk of neonatal death and lower rate of pulmonary complications in very low birth weight infants, respectively. ${ }^{42,43}$ A RCT by Elimian et al found similar effects of betamethasone and dexamethasone; however, dexamethasone was more effective in reducing the rate of IVH. ${ }^{44}$ A 2013 Cochrane review examined 12 RCTs comparing dexamethasone and betamethasone. Dexamethasone was found to be associated with a reduced risk of IVH and a shorter length of neonatal intensive care unit (NICU) admission. The author concluded that there is no clear advantage of one over the other and urged additional trials comparing the two corticosteroids. ${ }^{45}$

\section{Timing of Antenatal Corticosteroid}

The timing of ACS has been extensively studied. While the benefit of ACS is greatest 24 hours after administration and lasts for at least 7 days, even one $12 \mathrm{mg}$ dose of betamethasone is associated with decreased rates of IVH and neonatal death. ${ }^{46}$ Multiple studies and systematic reviews have also demonstrated a lack of efficacy of ACS after 7 days. ${ }^{47,48}$ In a retrospective cohort, delivery between 8 and 14 days was not found to be associated with increased perinatal morbidity when compared with delivery 1 to 7 days after ACS. ${ }^{49}$ Another retrospective cohort study found that delivery $>14$ days after ACS was associated with increased severity of neonatal respiratory illness compared with delivery 2 to 14 days after ACS. ${ }^{50}$

\section{Repeat Courses of Antenatal Corticosteroid}

The initial response to the lack of demonstrated efficacy after 7 to 14 days was to repeat the ACS courses weekly. However, there were concerns regarding the risks of repeat corticosteroids without solid evidence from RCTs of a neonatal benefit. Legitimate concerns of potential harm focused on growth restriction, decreased head circumference, and delayed psychomotor development associated with repeat corticosteroids. Since then, multiple RCTs have been performed to evaluate repeated ACS courses; the largest of which by Crowther et al (Australasian Collaborative Trial of Repeat Doses of Steroids [ACTORDS]), Guinn et al, McEvoy et al, Murphy et al (Multiple courses of antenatal corticosteroids for preterm birth [MACS]), and Wapner et al (NICHD), evaluated weekly or every 2 weeks administration. ${ }^{51-55}$ Results of the studies differed as some found no improvement in their primary neonatal outcome, ${ }^{52-55}$ while one found reduced neonatal morbidity. ${ }^{51}$ In the Guinn et al and Wapner et al trials, even though the primary composite outcome did not differ between the groups, some neonatal respiratory outcomes such as severe RDS were significantly lower in the repeat corticosteroid group. ${ }^{52,55}$ In regard to adverse outcomes, Crowther et al found a decrease in weight and head circumference at birth but no difference in mean weight, length, and head circumference at the time of hospital discharge. ${ }^{51}$ A subsequent secondary analysis revealed a rapid acceleration of postnatal growth 3 to 5 weeks after birth in those exposed to repeat corticosteroids. ${ }^{56}$ Murphy et al found that those exposed to repeat corticosteroids weighed less were shorter and had smaller head circumferences at birth. The relationship between corticosteroids and decreased fetal growth was later found to be dependent on the number of ACS courses. ${ }^{57}$ Wapner et al found that repeat corticosteroids $\geq 4$ courses significantly reduced birth weight. ${ }^{55}$

Just as with the short-term outcomes in the original studies, long-term outcomes differed between the studies that followed the children. The 18 to 24 months and 5 years follow-up of children from the MACS trial found no difference in risk of death or disability. ${ }^{58,59}$ However, after stratifying by gestational age at the time of birth, children born $\geq 37$ weeks and were exposed to multiple ACS therapy were at increased risk of neurodevelopment/neurosensory impairment by 5 years of age. ${ }^{60}$ Children in the NICHD trial followed up at 2 to 3 years of age had no differences in physical or neurocognitive measures; however, a higher rate of cerebral palsy was noted among children who had been exposed to repeat corticosteroids, but the difference was not statistically significant. ${ }^{61}$

Given these findings, investigators began to consider evaluating a single repeat ("rescue") course of ACS for women who remain at risk of preterm birth before 34 weeks. In 2001, a prospective, nonrandomized study demonstrated reduced RDS 
in neonates who received rescue steroids before delivery between 28 and 34 weeks' gestation. ${ }^{62}$ Peltoniemi et al found that a repeat course of betamethasone $>7$ days after a single course did not increase the rate of intact survival without RDS or severe IVH. They also noted that those who received a rescue course required more surfactant therapy for RDS. ${ }^{63}$ In 2010 , McEvoy et al reported an increase in respiratory compliance of newborns treated with a single repeat course of ACS $\geq 14$ days after the initial course. ${ }^{64}$ The definitive study of "rescue steroids" was published by Garite et al and found a significant reduction in composite neonatal morbidity for those treated with a single repeat course of steroids $\geq 14$ days after the initial course if they remained at risk for preterm birth before 33 weeks' gestation. ${ }^{65}$ No adverse growth outcomes were found in any of these three studies and a 2-year follow-up by Peltoniemi et al found no adverse effects on growth or neurodevelopmental outcomes in those treated with rescue steroids. ${ }^{66}$

Over the years, multiple systematic reviews have focused on the efficacy and safety of repeat corticosteroids. ${ }^{67-69}$ The most recent Cochrane review found that repeat corticosteroids 7 days or more after the initial course reduce the risk of RDS and serious adverse infant outcome. While repeat doses of corticosteroids were associated with a reduction in mean birth weight, the adjusted birth weight for gestational age was not different between the groups. Early childhood follow-up also did not demonstrate any differences between the groups. ${ }^{67}$

At present, ACOG recommends to consider a single repeat course of ACS in pregnant women less than $34^{0 / 7}$ weeks' gestation who are at risk of preterm delivery within the next 7 days, have intact membranes, and whose prior course of ACS was administered more than 14 days previously. They also acknowledge that rescue steroids could be provided as early as 7 days from the prior dose, and there is not enough evidence to recommend for or against rescue ACS in the setting of PPROM. ${ }^{31}$

\section{Review of Steroids after 34 Weeks}

Late preterm birth, delivery between $34^{0 / 7}$ and $36^{6 / 7}$ weeks' gestation, accounts for $71 \%$ of preterm births and $8.7 \%$ of all live births. These infants have longer hospital stays, higher hospital costs, and higher risk of other morbidities (hypoglycemia, hypothermia, feeding difficulty, and sudden infant death syndrome), ${ }^{70}$ as well as a threefold increase in neo- natal mortality when compared with term infants. ${ }^{71,72}$ More than one-third of these infants will be admitted to the NICU, most frequently for respiratory indications, and will constitute $33 \%$ of all NICU admissions. ${ }^{73,74}$

When compared with infants born from 39 to 40 weeks' gestation, infants born at 34 weeks were at higher risk of respiratory complications, including RDS/hyaline membrane disease (odds ratio [OR]: 40.1, 95\% CI: 32.0-50.3), transient tachypnea of the newborn (OR: 14.7, 95\% CI: 11.7-18.4), pneumonia (OR: $7.6,95 \% \mathrm{CI}: 5.2-11.2$ ), respiratory failure (OR: 10.5, 95\% CI: 6.9-16.1), and need for ventilator support (OR: $13.9,95 \% \mathrm{CI}: 11.0-17.6) .^{73}$ The risk of pulmonary morbidity decreased with advancing gestational age.

In the $1994 \mathrm{NIH}$ consensus statement, ACS was not recommended beyond 34 weeks because of the low risk of neonatal mortality, RDS, and IVH in this age group. ${ }^{3}$ A meta-analysis of RCTs published between 1972 and 1994 showed similar risk of RDS in the late preterm period when compared with infants delivered after 37 weeks (OR: 0.62, 95\% CI: 0.29-1.30). ${ }^{48}$ However, the pulmonary system may not be structurally or functionally mature in the late preterm period. ${ }^{75}$ While the literature supports increased risk of short-term respiratory morbidities of prematurity, the long-term outcomes are less clear. Some studies have shown an association between late preterm birth and childhood respiratory conditions, such as asthma and bronchitis; however, this has not been a consistent finding in the literature. ${ }^{76-78}$

Modern literature suggests a benefit for ACS for infants delivered in the late preterm period. Retrospective studies have reported that exposure to ACS before 34 weeks was beneficial to infants born in the late preterm period, and was associated with a significant reduction in respiratory morbidity, including RDS and need for ventilation. ${ }^{79,80}$

Though ACS administered in the late preterm period have shown improvement of fetal lung maturity testing, ${ }^{81}$ few studies have evaluated the clinical outcomes (-Table 1 ). Retrospective observational studies of immature fetal lung maturity testing and subsequent ACS administration have been inconsistent. Some reported benefit with decreased need for respiratory support, while other studies have reported no benefit and increased risk of hypoglycemia and presumed sepsis. ${ }^{82,83}$ Porto et al conducted a small RCT administering one course of betamethasone for women

Table 1 Summary of randomized controlled trials of antenatal corticosteroid administration in the late preterm period

\begin{tabular}{|l|l|l|l|l|l|l|}
\hline Study & Study design & TTN & BPD & RDS & $\begin{array}{l}\text { Mechanical } \\
\text { ventilation }\end{array}$ & $\begin{array}{l}\text { NICU } \\
\text { admission }\end{array}$ \\
\hline Balci et al $(2010)$ & $\begin{array}{l}100 \text { patients } \\
\text { Betamethasone } 12 \mathrm{mg} \times 1\end{array}$ & NA & NA & $\begin{array}{l}0.21 \\
(0.04-1.08)\end{array}$ & $\begin{array}{l}0.34 \\
(0.12-0.93)\end{array}$ & NA \\
\hline Porto et al $(2011)$ & $\begin{array}{l}273 \text { patients } \\
\text { Betamethasone } 12 \mathrm{mg} \times 2\end{array}$ & $\begin{array}{l}1.07 \\
(0.69-1.65)\end{array}$ & NA & $\begin{array}{l}1.82 \\
(0.17-19.8)\end{array}$ & $\begin{array}{l}1.82 \\
(0.17-19.8)\end{array}$ & $\begin{array}{l}0.99 \\
(0.71-1.39)\end{array}$ \\
\hline $\begin{array}{l}\text { Gyamfi-Bannerman } \\
\text { et al }(2016)\end{array}$ & $\begin{array}{l}1,427 \text { patients } \\
\text { Betamethasone } 12 \mathrm{mg} \times 2\end{array}$ & $\begin{array}{l}0.68 \\
(0.53-0.87)\end{array}$ & $\begin{array}{l}0.22 \\
(0.02-0.99)\end{array}$ & $\begin{array}{l}0.87 \\
(0.65-1.17)\end{array}$ & $\begin{array}{l}0.78 \\
(0.50-1.21)\end{array}$ & $\begin{array}{l}0.93 \\
(0.85-1.01)\end{array}$ \\
\hline
\end{tabular}

Abbreviations: BPD, bronchopulmonary dysplasia; NA, not assessed; NICU, neonatal intensive care unit; RDS, respiratory distress syndrome; TTN, transient tachypnea of the newborn.

Note: Odds ratio or relative risk (95\% confidence interval). 
at high risk of delivering between $34^{0 / 7}$ and $36^{6 / 7}$ weeks' gestational age. They reported a decrease in neonatal jaundice requiring phototherapy, but no significant difference in the risk of respiratory morbidity, mechanical ventilation, RDS, or NICU admission, although the authors admitted the trial was underpowered for the primary outcome and had a $14 \%$ rate of loss to follow-up. ${ }^{84}$ Balci et al reported that a single dose of betamethasone administered in the late preterm period was associated with a decrease in need for ventilation and resuscitation. ${ }^{85}$ RDS is not a common finding at these gestational ages, and these studies were underpowered to evaluate this. The real benefit of ACS may be in the reduction of other morbidities, and a larger study was necessary prior to recommending the use of corticosteroids in the late preterm period.

\section{Summary of the ALPS Trial}

A recent study by Gyamfi-Bannerman et al, "Antenatal Betamethasone for Women at Risk for Late Preterm Delivery (ALPS)," addressed this question by performing the largest study to date addressing the utility of ACS in the late preterm period. ${ }^{86}$ The Maternal-Fetal Medicine Units Network conducted a randomized, double-blind, placebo-controlled study at 17 academic centers of women with a singleton gestation at high risk for delivery in the late preterm period, including both indicated (hypertensive disease, ruptured membranes) or spontaneous delivery. These patients were randomized to receive two $12 \mathrm{mg}$ doses of intramuscular betamethasone, every 24 hours. Women were excluded from the trial if they were diagnosed with chorioamnionitis, previously received ACS, did not have adequate dating, or if delivery was expected within 12 hours of enrollment. Spontaneous preterm deliveries were more common than indicated deliveries. Tocolysis was not used in the study protocol; however, oxytocin was deferred for 12 hours after the first dose of betamethasone for patients at higher risk for delivery (ruptured membranes, cervical dilation $>3 \mathrm{~cm}$, or regular contractions). In both the study and control groups, 59 to $60 \%$ received the two doses of study medications. Follow-up of the infants was available until day of life 28 .

The primary outcome, respiratory support requirement in the first 72 hours (defined as continuous positive airway pressure or high flow nasal cannula for $>2$ hours) or severe respiratory morbidity (continuous positive airway pressure $>12$ hours or a fraction of inspired oxygen of $30 \%$ or greater for $>24$ hours) was less frequent in the betamethasone group than the placebo group (11.6 vs. 14.4\%, RR: $0.80,95 \% \mathrm{CI}: 0.66-0.97)$. In addition, those in the betamethasone group required less surfactant use, were less likely to need resuscitation, develop bronchopulmonary dysplasia, develop transient tachypnea of the newborn, and stay in the intermediate nursery/NICU for more than 3 days (RR: 0.89, 95\% CI: 0.80-0.98). There was no difference in the risk of RDS, apnea, or the need for mechanical ventilation. The ACS group had higher rates of neonatal hypoglycemia (24 vs. $15 \%$, RR: $1.60,95 \% \mathrm{CI}: 1.37-1.87$ ), but was not associated with longer hospitalization or adverse events.
There were no differences in chorioamnionitis/endometritis, cesarean delivery, or length of maternal hospitalization.

This study is the only RCT to assess bronchopulmonary dysplasia in former late preterm infants, which increases the risk of infection, rehospitalization, neurodevelopmental outcomes, cerebral palsy, and future pulmonary morbidity. ${ }^{87}$ Follow-up studies are being planned for the infant cohort.

\section{Long-Term Effects of Antenatal Corticosteroids}

In the last 10 to 15 years, the concept of fetal programming in relation to prenatal corticosteroid administration has garnered a lot of attention. The hypothesis of fetal programming posits that fetal adaptations due to maternal and fetal environment alter physiologic function throughout life. ${ }^{88}$ Several studies in animal models have found an association between ACS and long-term consequences such as hypertension, cardiac, metabolic, and vascular dysfunction, ${ }^{89}$ although clinical follow-up studies have not shown similar findings. ${ }^{90-92}$

Several human studies found short- and long-term alterations in the hypothalamic-pituitary-adrenal (HPA) axis in infants exposed to ACS. ${ }^{93-97}$ Changes in maternal and fetal leptin and adiponectin concentrations after betamethasone treatment have been described. ${ }^{98}$ Antenatal betamethasone use is associated with neonatal hypoglycemia and hyperbilirubinemia. ${ }^{99}$

While there are definite biochemical changes in infants exposed to ACS, the extensive clinical experience with a single dose of corticosteroids supports its benefit over any potential long-term risk. The short-term safety of a single corticosteroid dose has been previously described in this article. Since the landmark article on ACS was published in 1972, there have been multiple long-term follow-up studies. In a 20-year followup study, Dessens et al found no differences in several of intellectual, medical, or psychological variables. ${ }^{100}$ Alexander et al performed a follow-up study of children whose mothers were admitted for threatened preterm birth, but who ultimately delivered between 37 and 41 weeks' gestational age. The mothers who were admitted for threatened preterm labor had children who scored 6 to 7 points lower on IQ evaluations when compared with mothers who had uncomplicated pregnancies. When comparing the children who were and were not exposed to ACS prior to 34 weeks' gestation, there was no difference in IQ. The researchers concluded that the condition leading to preterm labor, not the single course of ACS, was associated with long-term cognitive changes. ${ }^{101}$

Several analyses by Dalziel et al found no effect of betamethasone on cardiovascular risk factors, lung function, cognitive functioning, or psychiatric morbidity 30 years after exposure. ${ }^{90-92}$ One of the studies found an increased insulin resistance in adults exposed to corticosteroids, but there was no difference in blood pressure, fasting lipids, body size, and HPA function. ${ }^{91}$ Another follow-up study found young adults exposed to in utero corticosteroids had increased aortic arch stiffness and altered glucose metabolism. The clinical implications of these findings has yet to be determined. ${ }^{102}$ In regard to neurodevelopmental outcomes, a recent metaanalysis by Sotiriadis et al discovered that a single course 
of ACS increased rates of intact survival, improved psychomotor development index scores, and reduced rates of severe disability and cerebral palsy in those delivered before 34 weeks' gestation. ${ }^{103}$ The most recent Cochrane reviews included long-term follow-up from four trials and found no reason to withhold ACS. ${ }^{7,28}$

\section{Recommendations for Late Preterm Steroids}

Based on the available literature, a single course of ACS is recommended for patients at high risk for late preterm birth to reduce the short-term respiratory morbidity of prematurity. This should be limited to patients who are unlikely to deliver within 12 hours of administration, as this may be insufficient time for corticosteroids to provide benefit. We recommend using the criteria of the ALPS trial to assess whether a patient is eligible for corticosteroids ( - Fig. 1). Due to increased risk of hypoglycemia, blood glucose levels should be monitored in the neonatal period.

\section{Remaining Knowledge Gaps for Late Preterm Steroids}

\section{Long-Term Effects}

As discussed previously, a majority of follow-up studies support the safety of a single course of ACS in the preterm period. Late preterm and early-term exposure needs further study as this is a critical time for cerebellar development and cerebral myelination. Animal studies have shown evidence of HPA axis dysregulation and structural changes, such as hippocampal degeneration, when exposed to ACS. ${ }^{88,104}$
There are few human studies evaluating these neurodevelopmental outcomes of ACS in the late preterm period. Stutchfield et al evaluated children between 6 and 10 years of age who were exposed to a single course of ACS prior to delivery at term. ${ }^{105}$ There were no differences in hyperactivity, emotional symptoms, conduct/peer problems, or level achievement in standardized testing; however, the children exposed to ACS were more likely to be perceived as being in the lower quartile of academic ability by the schools. This finding was a subjective outcome while all other objective behavioral and educational outcomes found no differences. As stated previously, a 30-year follow-up by Dalziel et al found no effect of betamethasone on cognitive functioning or psychiatric morbidity. ${ }^{90}$ This was a follow-up of the original RCT by Liggins and Howie which included subjects up to 37 weeks' gestation.

Further investigation is needed to study the effect of ACS administered in the late preterm period. Long-term followup is planned to evaluate the effect of betamethasone on neurodevelopmental outcomes of subjects included in the ALPS trial.

\section{Benefit of an Incomplete Course of Antenatal Corticosteroid}

As described previously, there is limited evidence that an incomplete course of ACS improves neonatal outcomes. In the ALPS trial, only $60 \%$ of the patients received both doses of the study or placebo drug. However, no subgroup analysis was performed on those who only received a single dose of betamethasone. Further studies are needed to determine if a single dose of ACS is beneficial in the late preterm period.

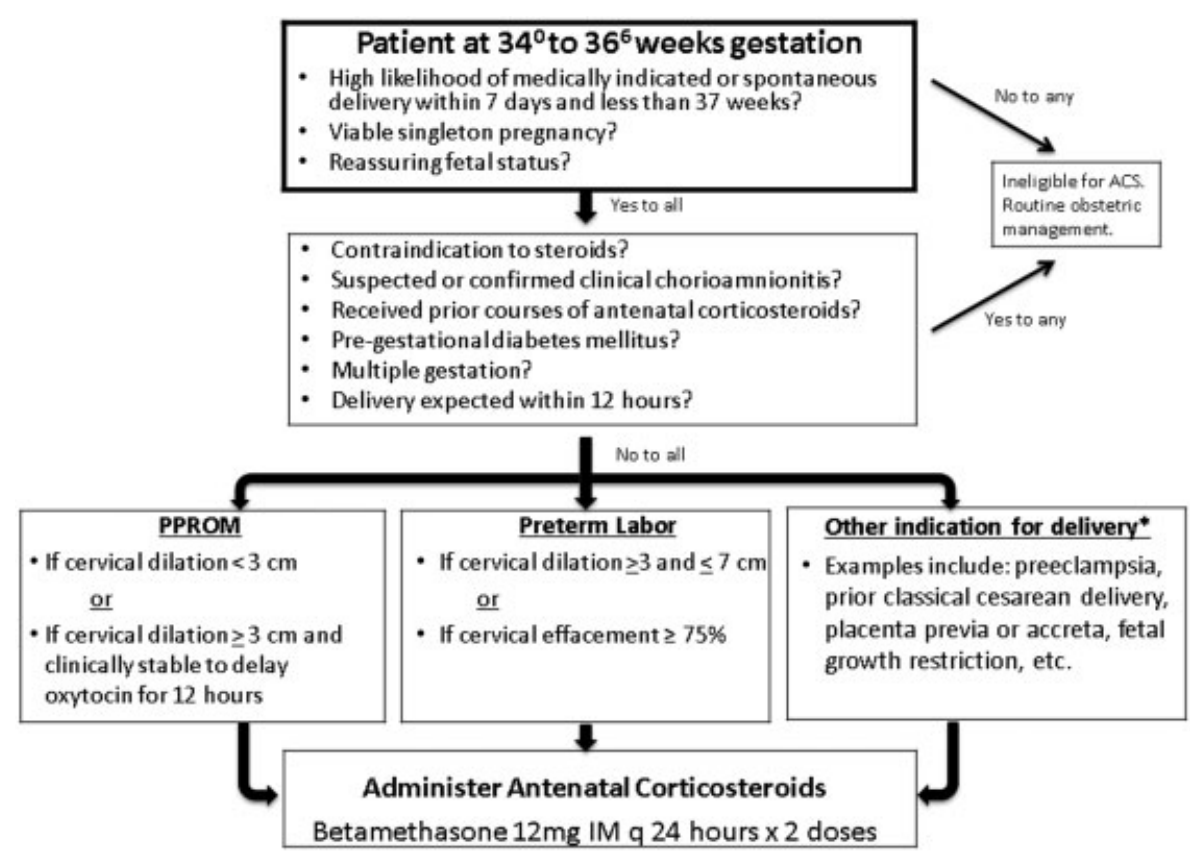

Fig. 1 Algorithm for eligibility for antenatal corticosteroids in the late preterm period. *Plan for first dose 2 to 7 days prior to anticipated cesarean delivery or induction of labor. ACS, antenatal corticosteroids; PPROM, preterm premature rupture of membranes; PTL, preterm labor. (Adapted from the Society for Maternal-Fetal Medicine preterm birth toolkit algorithm. Available at: https://www.smfm.org/publications/231smfm-preterm-birth-toolkit. September, 2016.) 


\section{Benefit of Repeated Course of Antenatal Corticosteroid}

For pregnant patients at high risk for delivery before 34 weeks' gestation, ACOG recommends the judicious use of a repeat course of corticosteroids. ${ }^{106}$ None of the aforementioned trials of late preterm ACS enrolled patients who had a prior course of ACS. No study has evaluated the efficacy of a repeat course of ACS in the late preterm period. Further studies are needed to determine if there is benefit of a repeat course of ACS in the late preterm period.

Supplementary information of examples cases for ACS use in the late preterm period is available as - Supplementary Material (available in online version).

\section{Conflict of Interest}

None.

\section{References}

1 Liggins GC, Howie RN. A controlled trial of antepartum glucocorticoid treatment for prevention of the respiratory distress syndrome in premature infants. Pediatrics 1972;50(04): 515-525

2 Papageorgiou AN, Colle E, Farri-Kostopoulos E, Gelfand MM. Incidence of respiratory distress syndrome following antenatal betamethasone: role of sex, type of delivery, and prolonged rupture of membranes. Pediatrics 1981;67(05):614-617

3 NIH Consensus Development Panel on the Effect of Corticosteroids for Fetal Maturation on Perinatal Outcomes. Effect of corticosteroids for fetal maturation on perinatal outcomes. JAMA 1995;273(05):413-418

4 Block MF, Kling OR, Crosby WM. Antenatal glucocorticoid therapy for the prevention of respiratory distress syndrome in the premature infant. Obstet Gynecol 1977;50(02):186-190

5 Crowley P, Chalmers I, Keirse MJ. The effects of corticosteroid administration before preterm delivery: an overview of the evidence from controlled trials. Br J Obstet Gynaecol 1990;97 (01):11-25

6 Committee on Obstetric Practice. ACOG committee opinion: antenatal corticosteroid therapy for fetal maturation. Obstet Gynecol 2002;99(5 Pt 1):871-873

7 Roberts D, Brown J, Medley N, Dalziel SR. Antenatal corticosteroids for accelerating fetal lung maturation for women at risk of preterm birth. Cochrane Database Syst Rev 2017;3:CD004454

8 Ecker JL, Kaimal A, Mercer BM, et al; American College of Obstetricians and Gynecologists and the Society for Maternal-Fetal Medicine. \#3: Periviable birth. Am J Obstet Gynecol 2015;213 (05):604-614

9 Stoll BJ, Hansen NI, Bell EF, et al; Eunice Kennedy Shriver National Institute of Child Health and Human Development Neonatal Research Network. Neonatal outcomes of extremely preterm infants from the NICHD Neonatal Research Network. Pediatrics 2010;126(03):443-456

10 Younge N, Goldstein RF, Bann CM, et al; Eunice Kennedy Shriver National Institute of Child Health and Human Development Neonatal Research Network. Survival and neurodevelopmental outcomes among periviable infants. N Engl J Med 2017;376(07): 617-628

11 Carlo WA, McDonald SA, Fanaroff AA, et al; Eunice Kennedy Shriver National Institute of Child Health and Human Development Neonatal Research Network. Association of antenatal corticosteroids with mortality and neurodevelopmental out- comes among infants born at 22 to 25 weeks' gestation. JAMA 2011;306(21):2348-2358

12 Abbasi S, Oxford C, Gerdes J, Sehdev H, Ludmir J. Antenatal corticosteroids prior to 24 weeks' gestation and neonatal outcome of extremely low birth weight infants. Am J Perinatol 2010; 27(01):61-66

13 Wong D, Abdel-Latif M, Kent A; NICUS Network. Antenatal steroid exposure and outcomes of very premature infants: a regional cohort study. Arch Dis Child Fetal Neonatal Ed 2014;99 (01):F12-F20

14 Miltaha HR, Fahey LM, Sajous CH, Morrison JC, Muraskas JK. Influence of perinatal factors in short- and long-term outcomes of infants born at 23 weeks of gestation. Am J Perinatol 2015;32 (07):627-632

15 Hayes EJ, Paul DA, Stahl GE, et al. Effect of antenatal corticosteroids on survival for neonates born at 23 weeks of gestation. Obstet Gynecol 2008;111(04):921-926

16 Raju TN, Mercer BM, Burchfield DJ, Joseph GF Jr. Periviable birth: executive summary of a joint workshop by the Eunice Kennedy Shriver National Institute of Child Health and Human Development, Society for Maternal-Fetal Medicine, American Academy of Pediatrics, and American College of Obstetricians and Gynecologists. Obstet Gynecol 2014;123(05):1083-1096

17 Eunice Kennedy Shriver National Institure of Child Health and Human Development. NICHD Neonatal Research Network (NRN): Extremely Preterm Birth Outcome Data. Available at: https://www1.nichd.nih.gov/epbo-calculator/Pages/epbo_case. aspx. Accessed April 1, 2018

18 Mitsiakos G, Kovacs L, Papageorgiou A. Are antenatal steroids beneficial to severely growth restricted fetuses? J Matern Fetal Neonatal Med 2013;26(15):1496-1499

19 Riskin-Mashiah S, Riskin A, Bader D, et al; Israel Neonatal Network. Antenatal corticosteroid treatment in singleton, small-for-gestational-age infants born at 24-31 weeks' gestation: a populationbased study. BJOG 2016;123(11):1779-1786

20 Torrance HL, Derks JB, Scherjon SA, Wijnberger LD, Visser GH. Is antenatal steroid treatment effective in preterm IUGR fetuses? Acta Obstet Gynecol Scand 2009;88(10):1068-1073

21 Niroomanesh S, Shojaei K, Moghadam SF, Mohammadi N, Rahimi Z, RezaeiKeyhanaei K. Effect of prenatal betamethasone on fetal, uteroplacental, and maternal blood flow velocity in pregnancies complicated by fetal growth restriction. Int J Gynaecol Obstet 2015;130(03):270-273

22 Nozaki AM, Francisco RP, Fonseca ES, Miyadahira S, Zugaib M. Fetal hemodynamic changes following maternal betamethasone administration in pregnancies with fetal growth restriction and absent end-diastolic flow in the umbilical artery. Acta Obstet Gynecol Scand 2009;88(03):350-354

23 Robertson MC, Murila F, Tong S, Baker LS, Yu VY, Wallace EM. Predicting perinatal outcome through changes in umbilical artery Doppler studies after antenatal corticosteroids in the growth-restricted fetus. Obstet Gynecol 2009;113(03):636-640

24 Simchen MJ, Alkazaleh F, Adamson SL, et al. The fetal cardiovascular response to antenatal steroids in severe early-onset intrauterine growth restriction. Am J Obstet Gynecol 2004;190(02): 296-304

25 Wijnberger LD, Bilardo CM, Hecher K, Stigter RH, Visser GH. Effect of antenatal glucocorticoid therapy on arterial and venous blood flow velocity waveforms in severely growth-restricted fetuses. Ultrasound Obstet Gynecol 2004;23(06):584-589

26 Senat MV, Ville Y. Effect of steroids on arterial Doppler in intrauterine growth retardation fetuses. Fetal Diagn Ther 2000;15(01):36-40

27 Vidaeff AC, Blackwell SC. Potential risks and benefits of antenatal corticosteroid therapy prior to preterm birth in pregnancies complicated by severe fetal growth restriction. Obstet Gynecol Clin North Am 2011;38(02):205-214 
28 Roberts D, Dalziel S. Antenatal corticosteroids for accelerating fetal lung maturation for women at risk of preterm birth. Cochrane Database Syst Rev 2006;(03):CD004454

29 Ballabh P, Lo ES, Kumari J, et al. Pharmacokinetics of betamethasone in twin and singleton pregnancy. Clin Pharmacol Ther 2002;71(01):39-45

30 Gyamfi C, Mele L, Wapner RJ, et al; Eunice Kennedy Shriver National Institute of Child Health and Human Development Maternal-Fetal Medicine Units Network. The effect of plurality and obesity on betamethasone concentrations in women at risk for preterm delivery. Am J Obstet Gynecol 2010;203(03):219. e1-219.e5

31 Committee on Obstetric Practice. Committee Opinion No. 713: antenatal corticosteroid therapy for fetal maturation. Obstet Gynecol 2017;130(02):e102-e109

32 Fisher SC, Kim SY, Sharma AJ, Rochat R, Morrow B. Is obesity still increasing among pregnant women? Prepregnancy obesity trends in 20 states, 2003-2009. Prev Med 2013;56(06):372-378

33 Branum AM, Kirmeyer SE, Gregory EC. Prepregnancy body mass index by maternal characteristics and state: data from the birth certificate, 2014. Natl Vital Stat Rep 2016;65(06):1-11

34 Shah DK, Missmer SA, Correia KF, Ginsburg ES. Pharmacokinetics of human chorionic gonadotropin injection in obese and normalweight women. J Clin Endocrinol Metab 2014;99(04):1314-1321

35 Cheymol G. Drug pharmacokinetics in the obese. Fundam Clin Pharmacol 1988;2(03):239-256

36 Hashima JN, Lai Y, Wapner RJ, et al; Eunice Kennedy Shriver National Institute of Child Health and Human Development Maternal-Fetal Medicine Units Network. The effect of maternal body mass index on neonatal outcome in women receiving a single course of antenatal corticosteroids. Am J Obstet Gynecol 2010;202(03):263.e1-263.e5

37 Gyamfi-Bannerman C, Son M. Preterm premature rupture of membranes and the rate of neonatal sepsis after two courses of antenatal corticosteroids. Obstet Gynecol 2014;124(05):999-1003

38 Elimian A, Verma U, Beneck D, Cipriano R, Visintainer P, Tejani N. Histologic chorioamnionitis, antenatal steroids, and perinatal outcomes. Obstet Gynecol 2000;96(03):333-336

39 Kent A, Lomas F, Hurrion E, Dahlstrom JE. Antenatal steroids may reduce adverse neurological outcome following chorioamnionitis: neurodevelopmental outcome and chorioamnionitis in premature infants. J Paediatr Child Health 2005;41(04):186-190

40 American College of Obstetricians and Gynecologists' Committee on Practice Bulletins-Obstetrics. Practice Bulletin No. 172: premature rupture of membranes. Obstet Gynecol 2016;128 (04):e165-e177

41 Crowley P. Antenatal corticosteroids-current thinking. BJOG 2003;110(Suppl 20):77-78

42 Lee BH, Stoll BJ, McDonald SA, Higgins RD; National Institute of Child Health and Human Development Neonatal Research Network. Adverse neonatal outcomes associated with antenatal dexamethasone versus antenatal betamethasone. Pediatrics 2006;117(05):1503-1510

43 Feldman DM, Carbone J, Belden L, Borgida AF, Herson V. Betamethasone vs dexamethasone for the prevention of morbidity in very-low-birthweight neonates. Am J Obstet Gynecol 2007;197 (03):284.e1-284.e4

44 Elimian A, Garry D, Figueroa R, Spitzer A, Wiencek V, Quirk JG. Antenatal betamethasone compared with dexamethasone (betacode trial): a randomized controlled trial. Obstet Gynecol 2007; 110(01):26-30

45 Brownfoot FC, Gagliardi DI, Bain E, Middleton P, Crowther CA. Different corticosteroids and regimens for accelerating fetal lung maturation for women at risk of preterm birth. Cochrane Database Syst Rev 2013;(08):CD006764

46 Elimian A, Figueroa R, Spitzer AR, Ogburn PL, Wiencek V, Quirk JG. Antenatal corticosteroids: are incomplete courses beneficial? Obstet Gynecol 2003;102(02):352-355
47 McLaughlin KJ, Crowther CA, Walker N, Harding JE. Effects of a single course of corticosteroids given more than 7 days before birth: a systematic review. Aust N Z J Obstet Gynaecol 2003;43 (02):101-106

48 Crowley PA. Antenatal corticosteroid therapy: a meta-analysis of the randomized trials, 1972 to 1994 . Am J Obstet Gynecol 1995; 173(01):322-335

49 Vermillion ST, Soper DE, Newman RB. Is betamethasone effective longer than 7 days after treatment? Obstet Gynecol 2001;97(04): 491-493

50 Ring AM, Garland JS, Stafeil BR, Carr MH, Peckman GS, Pircon RA. The effect of a prolonged time interval between antenatal corticosteroid administration and delivery on outcomes in preterm neonates: a cohort study. Am J Obstet Gynecol 2007;196 (05):457.e1-457.e6

51 Crowther CA, Haslam RR, Hiller JE, Doyle LW, Robinson JS; Australasian Collaborative Trial of Repeat Doses of Steroids (ACTORDS) Study Group. Neonatal respiratory distress syndrome after repeat exposure to antenatal corticosteroids: a randomised controlled trial. Lancet 2006;367(9526):1913-1919

52 Guinn DA, Atkinson MW, Sullivan L, et al. Single vs weekly courses of antenatal corticosteroids for women at risk of preterm delivery: a randomized controlled trial. JAMA 2001;286(13):1581-1587

53 McEvoy C, Bowling S, Williamson K, et al. The effect of a single remote course versus weekly courses of antenatal corticosteroids on functional residual capacity in preterm infants: a randomized trial. Pediatrics 2002;110(2 Pt 1):280-284

54 Murphy KE, Hannah ME, Willan AR, et al; MACS Collaborative Group. Multiple courses of antenatal corticosteroids for preterm birth (MACS): a randomised controlled trial. Lancet 2008;372 (9656):2143-2151

55 Wapner RJ, Sorokin Y, Thom EA, et al; National Institute of Child Health and Human Development Maternal Fetal Medicine Units Network. Single versus weekly courses of antenatal corticosteroids: evaluation of safety and efficacy. Am J Obstet Gynecol 2006; 195(03):633-642

56 Battin M, Bevan C, Harding J. Growth in the neonatal period after repeat courses of antenatal corticosteroids: data from the ACTORDS randomised trial. Arch Dis Child Fetal Neonatal Ed 2012;97(02):F99-F105

57 Murphy KE, Willan AR, Hannah ME, et al; Multiple Courses of Antenatal Corticosteroids for Preterm Birth Study Collaborative Group. Effect of antenatal corticosteroids on fetal growth and gestational age at birth. Obstet Gynecol 2012;119(05):917-923

58 Asztalos EV, Murphy KE, Hannah ME, et al; Multiple Courses of Antenatal Corticosteroids for Preterm Birth Study Collaborative Group. Multiple courses of antenatal corticosteroids for preterm birth study: 2-year outcomes. Pediatrics 2010;126(05):e1045-e1055

59 Asztalos EV, Murphy KE, Willan AR, et al; MACS-5 Collaborative Group. Multiple courses of antenatal corticosteroids for preterm birth study: outcomes in children at 5 years of age (MACS-5). JAMA Pediatr 2013;167(12):1102-1110

60 Asztalos E, Willan A, Murphy K, et al; MACS-5 Collaborative Group. Association between gestational age at birth, antenatal corticosteroids, and outcomes at 5 years: multiple courses of antenatal corticosteroids for preterm birth study at 5 years of age (MACS-5). BMC Pregnancy Childbirth 2014;14:272

61 Wapner RJ, Sorokin Y, Mele L, et al; National Institute of Child Health and Human Development Maternal-Fetal Medicine Units Network. Long-term outcomes after repeat doses of antenatal corticosteroids. N Engl J Med 2007;357(12):1190-1198

62 Vermillion ST, Bland ML, Soper DE. Effectiveness of a rescue dose of antenatal betamethasone after an initial single course. Am J Obstet Gynecol 2001;185(05):1086-1089

63 Peltoniemi OM, Kari MA, Tammela O, et al; Repeat Antenatal Betamethasone Study Group. Randomized trial of a single repeat dose of prenatal betamethasone treatment in imminent preterm birth. Pediatrics 2007;119(02):290-298 
64 McEvoy C, Schilling D, Peters D, et al. Respiratory compliance in preterm infants after a single rescue course of antenatal steroids: a randomized controlled trial. Am J Obstet Gynecol 2010;202 (06):544.e1-544.e9

65 Garite TJ, Kurtzman J, Maurel K, Clark R Obstetrix Collaborative Research Network. Impact of a 'rescue course' of antenatal corticosteroids: a multicenter randomized placebo-controlled trial. Am J Obstet Gynecol 2009;200(03):248.e1-248.e9

66 Peltoniemi OM, Kari MA, Lano A, et al; Repeat Antenatal Betamethasone (RepeatBM) Follow-Up Study Group. Two-year followup of a randomised trial with repeated antenatal betamethasone. Arch Dis Child Fetal Neonatal Ed 2009;94(06):F402-F406

67 Crowther CA, McKinlay CJ, Middleton P, Harding JE. Repeat doses of prenatal corticosteroids for women at risk of preterm birth for improving neonatal health outcomes. Cochrane Database Syst Rev 2011;(06):CD003935

68 Peltoniemi OM, Kari MA, Hallman M. Repeated antenatal corticosteroid treatment: a systematic review and meta-analysis. Acta Obstet Gynecol Scand 2011;90(07):719-727

69 McKinlay CJ, Crowther CA, Middleton P, Harding JE. Repeat antenatal glucocorticoids for women at risk of preterm birth: a Cochrane Systematic Review. Am J Obstet Gynecol 2012;206 (03):187-194

70 Raju TN, Higgins RD, Stark AR, Leveno KJ. Optimizing care and outcome for late-preterm (near-term) infants: a summary of the workshop sponsored by the National Institute of Child Health and Human Development. Pediatrics 2006;118(03):1207-1214

71 Darcy AE. Complications of the late preterm infant. J Perinat Neonatal Nurs 2009;23(01):78-86

72 Engle WA. Morbidity and mortality in late preterm and early term newborns: a continuum. Clin Perinatol 2011;38(03):493-516

73 Hibbard JU, Wilkins I, Sun L, et al; Consortium on Safe Labor. Respiratory morbidity in late preterm births. JAMA 2010;304 (04):419-425

74 Mally PV, Bailey S, Hendricks-Muñoz KD. Clinical issues in the management of late preterm infants. Curr Probl Pediatr Adolesc Health Care 2010;40(09):218-233

75 Shields JR, Resnik R. Fetal lung maturation and the antenatal use of glucocorticoids to prevent the respiratory distress syndrome. Obstet Gynecol Surv 1979;34(05):343-363

76 Odibo IN, Bird TM, McKelvey SS, Sandlin A, Lowery C, Magann EF. Childhood respiratory morbidity after late preterm and early term delivery: a study of Medicaid patients in South Carolina. Paediatr Perinat Epidemiol 2016;30(01):67-75

77 Voge GA, Katusic SK, Qin R, Juhn YJ. Risk of asthma in late preterm infants: a propensity score approach. J Allergy Clin Immunol Pract 2015;3(06):905-910

78 Abe K, Shapiro-Mendoza CK, Hall LR, Satten GA. Late preterm birth and risk of developing asthma. J Pediatr 2010;157(01):74-78

79 Ventolini G, Neiger R, Mathews L, Adragna N, Belcastro M. Incidence of respiratory disorders in neonates born between 34 and 36 weeks of gestation following exposure to antenatal corticosteroids between 24 and 34 weeks of gestation. Am J Perinatol 2008;25 (02):79-83

80 Eriksson L, Haglund B, Ewald U, Odlind V, Kieler H. Health consequences of prophylactic exposure to antenatal corticosteroids among children born late preterm or term. Acta Obstet Gynecol Scand 2012;91(12):1415-1421

81 Shanks A, Gross G, Shim T, Allsworth J, Sadovsky Y, Bildirici I. Administration of steroids after 34 weeks of gestation enhances fetal lung maturity profiles. Am J Obstet Gynecol 2010;203(01): 47.e1-47.e5

82 Yinon Y, Haas J, Mazaki-Tovi S, et al. Should patients with documented fetal lung immaturity after 34 weeks of gestation be treated with steroids? Am J Obstet Gynecol 2012;207(03): 222.e1-222.e4

83 Kamath-Rayne BD, DeFranco EA, Marcotte MP. Antenatal steroids for treatment of fetal lung immaturity after 34 weeks of gestation: an evaluation of neonatal outcomes. Obstet Gynecol 2012;119(05):909-916

84 Porto AM, Coutinho IC, Correia JB, Amorim MM. Effectiveness of antenatal corticosteroids in reducing respiratory disorders in late preterm infants: randomised clinical trial. BMJ 2011;342: d1696

85 Balci O, Ozdemir S, Mahmoud AS, Acar A, Colakoglu MC. The effect of antenatal steroids on fetal lung maturation between the 34th and 36th week of pregnancy. Gynecol Obstet Invest 2010;70 (02):95-99

86 Gyamfi-Bannerman C, Thom EA, Blackwell SC, et al; NICHD Maternal-Fetal Medicine Units Network. Antenatal betamethasone for women at risk for late preterm delivery. N Engl J Med 2016;374(14):1311-1320

87 Kinsella JP, Greenough A, Abman SH. Bronchopulmonary dysplasia. Lancet 2006;367(9520):1421-1431

88 Moisiadis VG, Matthews SG. Glucocorticoids and fetal programming part 1: Outcomes. Nat Rev Endocrinol 2014;10(07): 391-402

89 Singh RR, Cuffe JS, Moritz KM. Short- and long-term effects of exposure to natural and synthetic glucocorticoids during development. Clin Exp Pharmacol Physiol 2012;39(11):979-989

90 Dalziel SR, Lim VK, Lambert A, et al. Antenatal exposure to betamethasone: psychological functioning and health related quality of life 31 years after inclusion in randomised controlled trial. BMJ 2005;331(7518):665

91 Dalziel SR, Walker NK, Parag V, et al. Cardiovascular risk factors after antenatal exposure to betamethasone: 30-year followup of a randomised controlled trial. Lancet 2005;365(9474): 1856-1862

92 Dalziel SR, Rea HH, Walker NK, et al. Long term effects of antenatal betamethasone on lung function: 30 year follow up of a randomised controlled trial. Thorax 2006;61(08):678-683

$93 \mathrm{Ng}$ PC, Wong GW, Lam CW, et al. Effect of multiple courses of antenatal corticosteroids on pituitary-adrenal function in preterm infants. Arch Dis Child Fetal Neonatal Ed 1999;80(03): F213-F216

94 Buyukkayhan D, Ozturk MA, Kurtoglu S, Koklu E, Yikilmaz A. Effect of antenatal betamethasone use on adrenal gland size and endogenous cortisol and 17-hydroxyprogesterone in preterm neonates. J Pediatr Endocrinol Metab 2009;22(11):1027-1031

95 Davis EP, Waffarn F, Sandman CA. Prenatal treatment with glucocorticoids sensitizes the hpa axis response to stress among full-term infants. Dev Psychobiol 2011;53(02):175-183

96 Ashwood PJ, Crowther CA, Willson KJ, et al. Neonatal adrenal function after repeat dose prenatal corticosteroids: a randomized controlled trial. Am J Obstet Gynecol 2006;194(03): 861-867

97 Alexander N, Rosenlöcher F, Stalder T, et al. Impact of antenatal synthetic glucocorticoid exposure on endocrine stress reactivity in term-born children. J Clin Endocrinol Metab 2012;97(10): 3538-3544

98 Marinoni E, Letizia C, Ciardo F, Corona G, Moscarini M, Di Iorio R. Effects of prenatal betamethasone administration on leptin and adiponectin concentrations in maternal and fetal circulation. Am J Obstet Gynecol 2008;199(02):141.e1-141.e6

99 Pettit KE, Tran SH, Lee E, Caughey AB. The association of antenatal corticosteroids with neonatal hypoglycemia and hyperbilirubinemia. J Matern Fetal Neonatal Med 2014;27(07): 683-686

100 Dessens AB, Haas HS, Koppe JG. Twenty-year follow-up of antenatal corticosteroid treatment. Pediatrics 2000;105(06):E77

101 Alexander N, Rosenlöcher F, Dettenborn L, et al. Impact of antenatal glucocorticoid therapy and risk of preterm delivery on intelligence in term-born children. J Clin Endocrinol Metab 2016;101(02):581-589

102 Kelly BA, Lewandowski AJ, Worton SA, et al. Antenatal glucocorticoid exposure and long-term alterations in aortic 
Dixon et al.

function and glucose metabolism. Pediatrics 2012;129(05): e1282-e1290

103 Sotiriadis A, Tsiami A, Papatheodorou S, Baschat AA, Sarafidis K, Makrydimas G. Neurodevelopmental outcome after a single course of antenatal steroids in children born preterm: a systematic review and meta-analysis. Obstet Gynecol 2015;125(06):1385-1396

104 Uno H, Lohmiller L, Thieme C, et al. Brain damage induced by prenatal exposure to dexamethasone in fetal rhesus macaques. I. Hippocampus. Brain Res Dev Brain Res 1990;53(02):157-167
105 Stutchfield PR, Whitaker R, Gliddon AE, Hobson L, Kotecha S, Doull IJ. Behavioural, educational and respiratory outcomes of antenatal betamethasone for term caesarean section (ASTECS trial). Arch Dis Child Fetal Neonatal Ed 2013;98(03): F195-F200

106 American College of Obstetricians and Gynecologists' Committee on Practice Bulletins-Obstetrics. Practice Bulletin No. 171: management of preterm labor. Obstet Gynecol 2016;128(04): e155-e164 